OPEN ACCESS

Edited by:

Manfred B. Lutz,

University of Würzburg,

Germany

Reviewed by:

Veronika Lukacs-Kornek, Saarland University, Germany

Karsten Mahnke,

University Hospital Heidelberg,

Germany

${ }^{*}$ Correspondence:

Andrew F. G. Quest

aquest@med.uchile.cl;

Alvaro Lladser

alladser@cienciavida.org

Specialty section:

This article was submitted to

Antigen Presenting

Cell Biology,

a section of the journal

Frontiers in Immunology

Received: 24 August 2017 Accepted: 30 November 2017

Published: 13 December 2017

Citation:

Oyarce C, Cruz-Gomez S,

Galvez-Cancino $F$, Vargas $P$,

Moreau HD, Diaz-Valdivia N, Diaz J,

Salazar-Onfray FA, Pacheco $R$,

Lennon-Dumenil AM, Quest AFG and

Lladser A (2017) Caveolin-1

Expression Increases upon

Maturation in Dendritic Cells and

Promotes Their Migration to Lymph

Nodes Thereby Favoring the Induction of $\mathrm{CD}^{+} \mathrm{T}$ Cell Responses.

Front. Immunol. 8:1794.

doi: 10.3389/fimmu.2017.01794

\section{Caveolin-1 Expression Increases upon Maturation in Dendritic Cells and Promotes Their Migration to Lymph Nodes Thereby Favoring the Induction of $\mathrm{CD}^{+} \mathrm{T}$ Cell Responses}

\author{
Cesar Oyarce ${ }^{1,2}$, Sebastián Cruz-Gomez ${ }^{1,2}$, Felipe Galvez-Cancino', Pablo Vargas ${ }^{3}$, \\ Hélène D. Moreau ${ }^{4}$, Natalia Diaz-Valdivia ${ }^{2}$, Jorge Diaz², Flavio Andres Salazar-Onfray ${ }^{5}$, \\ Rodrigo Pacheco ${ }^{6,7}$, Ana Maria Lennon-Dumenil ${ }^{4}$, Andrew F. G. Quest ${ }^{2 *}$ \\ and Alvaro Lladser ${ }^{1 *}$

\begin{abstract}
${ }^{1}$ Laboratory of Gene Immunotherapy, Fundación Ciencia \& Vida, Santiago, Chile, ${ }^{2}$ Laboratory of Cellular Communication, Advanced Center for Chronic Diseases (ACCDiS) and Center for Molecular Studies of the Cell (CEMC), Program in Cell and National de la Santé et de la Recherche Médicale Unité 144, Institut Curie/CNRS, Paris, France, ${ }^{4}$ Institut National de la Santé et de la Recherche Médicale Unité 932, Institut Curie/CNRS, Paris, France, ${ }^{5}$ Program in Immunology, Faculty of Medicine, Biomedical Sciences Institute (ICBM), University of Chile, Santiago, Chile, ${ }^{6}$ Laboratory of Neuroimmunology, Fundación Ciencia \& Vida, Santiago, Chile, 'Departamento de Ciencias Biológicas, Facultad de Ciencias Biológicas,
\end{abstract} \\ Molecular Biology, Faculty of Medicine, Biomedical Sciences Institute (ICBM), University of Chile, Santiago, Chile, ${ }^{3}$ Institut \\ Universidad Andres Bello, Santiago, Chile
}

Dendritic cell (DC) trafficking from peripheral tissues to lymph nodes (LNs) is a key step required to initiate $T$ cell responses against pathogens as well as tumors. In this context, cellular membrane protrusions and the actin cytoskeleton are essential to guide DC migration towards chemotactic signals. Caveolin-1 (CAV1) is a scaffolding protein that modulates signaling pathways leading to remodeling of the actin cytoskeleton and enhanced migration of cancer cells. However, whether CAV1 is relevant for DC function and specifically for DC migration to LNs is unknown. Here, we show that CAV1 expression is upregulated in DCs upon LPS- and TNF- $\alpha$-induced maturation. CAV1 deficiency did not affect differentiation, maturation, or the ability of DCs to activate CD8 ${ }^{+} T$ cells in vitro. However, CAV1-deficient (CAV1-/-) DCs displayed reduced in vivo trafficking to draining LNs in control and inflammatory conditions. In vitro, CAV1-/- DCs showed reduced directional migration in CCL21 gradients in transwell assays without affecting migration velocity in confined microchannels or three-dimensional collagen matrices. In addition, $\mathrm{CAV}^{-1-}$ DCs displayed reduced activation of the small GTPase Rac1, a regulator of actin cytoskeletal remodeling, and lower numbers of F-actin-forming protrusions. Furthermore, mice adoptively transferred with peptide-pulsed $\mathrm{CAV} 1^{-/-} \mathrm{DCs}$ showed reduced $\mathrm{CD} 8^{+} \mathrm{T}$ cell responses and antitumor protection. Our results suggest that CAV1 promotes the activation of Rac1 and the formation of membrane protrusions that favor DC chemotactic trafficking toward LNs where they can initiate cytotoxic $T$ cell responses.

Keywords: caveolin-1, dendritic cells, migration, chemotaxis, $C D 8^{+} \mathbf{T}$ cell activation, antitumor immune response 


\section{INTRODUCTION}

Dendritic cells (DCs) are professional antigen-presenting cells specialized in initiating adaptive $\mathrm{T}$ cell responses. DCs circulate and patrol peripheral tissues, taking up protein antigens and processing them into small peptides that are presented at the cell surface by major histocompatibility complex (MHC) molecules. After recognition of pathogen- or danger-associated signals, DCs maturate and migrate via lymphatic vessels to secondary lymphoid organs [i.e., lymph nodes (LNs)] where they activate antigen-specific naïve T cells (1). DC maturation induces upregulation of several proteins, including co-stimulatory molecules and cytokines (2) and also increases DC trafficking toward secondary lymphoid organs by increasing polarized migration and upregulating chemokine receptors, such as CCR7 $(3,4)$. Increased CCR7 expression allows DCs to detect increasing concentrations of CCL19/CCL21 $(5,6)$, which promotes haptotactic DC migration to the lymph vessels and entering into $\mathrm{T}$ cell rich areas of LNs (paracortex) $(7,8)$. Trafficking of DCs from peripheral tissues to LNs involves several sequential steps: (1) mobilization, (2) detachment, (3) interstitial migration, (4) entry into the afferent lymphatics, and (5) transit via the lymph (9).

To migrate through epithelial barriers, DCs extend F-actin membrane protrusions at the cell front to associate via integrins with extracellular substrates. These points of contact are coupled to the cytoskeleton to transduce the internal force that is generated when myosin II contracts the actin network, allowing retrograde traction forces on the integrins to move the cell. Then to migrate through three-dimensional matrices, DCs use adhesion-independent amoeboid migration, which is driven by protrusive flowing of the actin network at the leading edge of the cell. Myosin II-dependent contraction of the trailing edge is required when DCs need to pass through narrow gaps. On their way to LNs, DCs also need to transmigrate into lymph vessels (3) and proteins expressed in the lymph vessels promote actomyosin-mediated cellular contraction in DCs $(10,11)$, thereby enhancing cell migration across the lymphatic endothelium (12). Once DCs reach the lumen of lymph vessels, chemokine signals like CCL21 gradients (13) and mechanical forces like hydrostatic pressure or friction (14) guide the "squeezing and flowing" of the actin cytoskeleton that defines amoeboid DC migration (13). Finally, DCs enter the LN and transmigrate to the paracortex ( $\mathrm{T}$ cell rich area) (15), where they activate T cells. As indicated above, regulation of actin cytoskeleton remodeling is important in every step of DC trafficking (14). Indeed, it has been suggested that actin flow may determine cell speed and persistency (16), highlighting the importance of actin cytoskeleton dynamics during DC trafficking. Such fine-tuned control is achieved mostly by the small GTPases Rho (17), Cdc42 (18), and Rac1 (19). However, despite recent progress in this field, our understanding of these events in DCs is limited, and additional pathways or molecules that promote DC trafficking remain to be defined.

Caveolin-1 (CAV1) is a membrane-bound scaffolding protein implicated in caveolae formation (20) that interacts with and controls the activity of a large number of proteins involved in signaling pathways relevant to growth, survival and proliferation in different cell types (21-24). Accumulating evidence supports a role for CAV1 in cell migration. Indeed, it was shown that directional persistency and chemotaxis are reduced in CAV1-deficient fibroblasts (25). In cancer cells, CAV1 expression promotes cell migration and invasion in vitro $(26,27)$ and metastasis in vivo $(28,29)$. The molecular mechanisms that operate downstream of CAV1 in these models, involve an increase in Rac1 activity via activation of the recently identified CAV1/p85 $\alpha /$ Rab5/Tiam1/Rac1 signaling axis (27). It was largely assumed that caveolin proteins were not expressed in leukocytes. However, emerging evidence indicates that they can be found in myeloid and, in some particular cases, lymphoid cells $(30,31)$. A few reports have shown CAV1 expression in DCs, but its role remains unclear. Some reports suggest that CAV1 is involved in caveolae-dependent endocytosis $(32,33)$. Another study suggests that CAV1 recruits and suppresses iNOS, thereby decreasing NO production and suppressing DC function during HSV-1 infection (34). Also, CAV1 has been shown to promote HIV-1 capture and lysosomal degradation by Langerhans cells (LCs), restricting viral integration and subsequent spreading (35). Interestingly, stimulation of human LCs with TNF- $\alpha$ increased CAV1 transcript levels (36), suggesting that CAV1 expression may be upregulated upon maturation. Taken together, these observations suggest that CAV1 might be relevant for DC function by modulating their migratory capacity.

In this study, we describe for the first time that CAV1 expression is upregulated upon DC maturation. Using CAV1-deficient $\left(\mathrm{CAV}^{-l-}\right)$ mice, we show that $\mathrm{CAV} 1^{-/-} \mathrm{DCs}$ displayed reduced in vivo trafficking to draining LNs in steady state and inflammatory conditions. CAV $1^{-/-}$DCs showed reduced migration toward CCL21 gradients in transwell assays, decreased Racl activity and lower numbers of F-actin-forming protrusions. Furthermore, peptide-pulsed $\mathrm{CAV}^{-/-}$DCs elicited reduced $\mathrm{CD}^{+} \mathrm{T}$ cell responses in vivo and poorer antitumor protection. Overall, our results suggest that CAV1 promotes migration of DCs to LNs, likely through Rac1-dependent actin cytoskeleton remodeling, to elicit effective $\mathrm{T}$ cell responses.

\section{RESULTS}

\section{CAV1 Expression is Upregulated upon DC Maturation}

To determine what happens to CAV1 expression upon maturation, we first evaluated by Western blot analysis CAV1 expression in purified spleen DCs (Sp-DCs) and bone marrow-derived DCs (BM-DCs) following stimulation with LPS and TNF- $\alpha$ (Figure 1; Figures S1A,B in Supplementary Material). CAV1 expression was increased in Sp-DCs after $6 \mathrm{~h}$ of LPS stimulation (Figures 1A; Figure S1A in Supplementary Material). Both LPS and TNF- $\alpha$ induced a time-dependent increase in CAV1 expression following 6-24 h of stimulation in BM-DCs (Figures 1B,C; Figure S1B in Supplementary Material). Since TNF- $\alpha$ secretion is induced by LPS (Figure S1C in Supplementary Material), we next evaluated whether autocrine TNF- $\alpha$ was involved in LPSinduced CAV1 upregulation. To this end, TNF- $\alpha$ was blocked using a neutralizing antibody present for 6- or $24 \mathrm{~h}$ during 

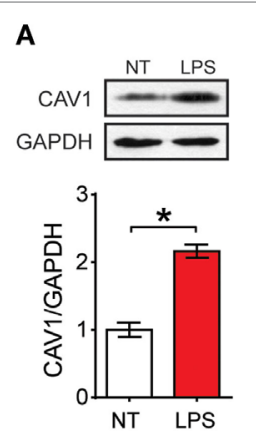
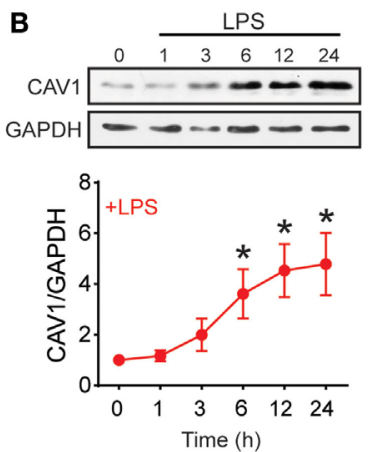
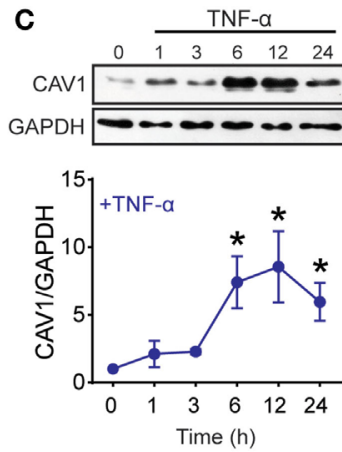
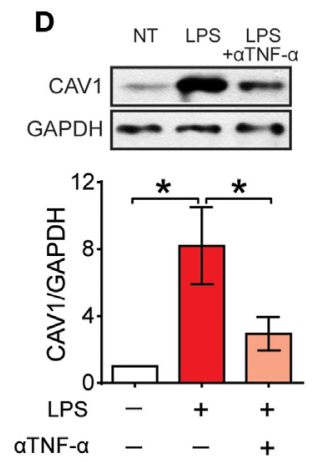

FIGURE 1 | Caveolin-1 (CAV1) is expressed in dendritic cells (DCs) and upregulated upon maturation. CAV1 expression in DCs was assessed by Western blotting. GAPDH and actin were used as loading controls. CAV1 protein expression was quantified by densitometry analysis and standardized to loading control. Values normalized to untreated controls (NT) are shown. (A) Spleen DCs purified from wild-type mice were treated with LPS (100 ng/ml) for 6 h. (B,C) Bone marrow-derived DCs (BM-DCs) were stimulated with LPS (100 ng/ml) or TNF- $\alpha$ (20 ng/ml) for 0, 1, 3, 6, 12, or 24 h. (D) BM-DCs were treated with LPS (100 ng/ml) alone or in combination with a TNF- $\alpha$ blocking antibody $(5 \mu \mathrm{g} / \mathrm{ml})$ for $24 \mathrm{~h}$. Values are presented as the mean \pm SEM. ${ }^{*} p<0.05$; $n=3$ independent experiments.

LPS stimulation. As shown in Figure 1D, the TNF- $\alpha$ blocking antibody reduced by over 50\% CAV1 upregulation after $24 \mathrm{~h}$ stimulation. However, blocking TNF- $\alpha$ did not change LPS-induced upregulation of CAV1 at an earlier time point $(6 \mathrm{~h})$ following LPS treatment (Figure S1D in Supplementary Material), indicating that LPS-induced upregulation of CAV1 initially does not require TNF- $\alpha$, but that secreted TNF- $\alpha$ then plays a predominant role at later time points.

To assess the role of CAV1 in DC function, we used a CAV1 null $\left(\mathrm{CAV}^{-1-}\right)$ mouse model (37). To validate the model, we first determined the frequency of DCs present in spleen, LNs and skin (as an example of peripheral tissue). We found that DC frequency was the same in both $\mathrm{CAV}^{-/-}$and wild-type (WT) mice for all the tested tissues (Figures S2A-C in Supplementary Material). Moreover, no differences were observed in terms of viability, differentiation, expression of lineage markers, and co-stimulatory molecules, as well as cytokine secretion when comparing BM-DCs generated from $\mathrm{CAV}^{-/-}$with DCs from WT mice (Figure S2D in Supplementary Material). We also evaluated co-stimulatory molecule expression and neither CD14, CD40, CD86, CD38, PD-L1 nor MHC-I expression changed when comparing WT and $\mathrm{CAV}^{-/-} \mathrm{DCs}$, irrespective of their maturation status. The only difference detected was a minor reduction in CD80 and CCR7 expression in immature $\mathrm{CAV}^{-1-}$ DCs when compared with WT DCs. This difference was not evident when analyzing mature DCs though. Furthermore, cytokine secretion (IL-6, IL-12, and TNF- $\alpha$ ) was the same for control or LPS-maturated WT or CAV1 $1^{-1-}$ DCs. Given that a key feature of DCs is to activate T cells, we evaluated whether CAV1 participates in DC-mediated $\mathrm{CD}^{+} \mathrm{T}$ cell activation. In agreement with our previous data, both WT and CAV $1^{-/-} \mathrm{DCs}$ pulsed with different concentrations of the $\mathrm{OVA}_{257-264}$ peptide (SIINFEKL) were equally efficient at inducing the proliferation of CFSE-stained $\mathrm{OVA}_{257-264}$-specific OT-I CD8 ${ }^{+} \mathrm{T}$ cells (Figure S3A in Supplementary Material). These results suggest that CAV1 deficiency in DCs does not affect either differentiation, maturation or the ability to activate $\mathrm{CD}^{+} \mathrm{T}$ cells in vitro.

\section{CAV1 Promotes DC Trafficking to LNs}

To identify a possible role for CAV1 in DC function in vivo, we tested whether CAV1 was involved in the trafficking of DCs from the periphery to LNs by performing the FITC painting assay. To this end, mice were inoculated with a FITC-containing solution at two different sites (left and right) of the lower back (38). To further induce inflammation and enhance skin DC migration, one site was additionally treated with dibutyl phthalate (DBP), which is a well-known skin irritant that promotes DC migration (39). As summarized in the scheme (Figure 2A), the accumulation of FITC-positive migratory DCs $\left(\mathrm{FITC}^{+} \mathrm{CD} 11 \mathrm{c}^{+} \mathrm{MHC}-\mathrm{II}^{\text {high }}\right.$ ) in the inguinal LN was evaluated by flow cytometry after $20 \mathrm{~h}$. Viable cells were gated for co-expression of CD11c and MHC-II to identify DCs (gating strategy shown in Figure S2D in Supplementary Material). As shown, the absence of CAV1 drastically impaired DC trafficking to the inguinal LNs in both control and inflammatory conditions (Figure 2B). Indeed, 1.6\% of WT DCs reached LNs as compared with only $0.1 \%$ for $\mathrm{CAV}^{-/-} \mathrm{DCs}$, indicating that the lack of CAV 1 in DCs impaired almost completely migration in the control condition (Figure 2B, left panels). DBP-induced migration of WT DCs increased up to $25 \%$ as compared with only $10 \%$ for $\mathrm{CAV}^{-/-}$DCs (Figure 2B, right panels). These results suggest that CAV1 expression is fundamental for DC trafficking from skin to the draining LNs.

As DC prevalence was similar in the skin of WT and CAV1 ${ }^{-1-}$ mice (Figure S2C in Supplementary Material), impaired DC trafficking to the LNs in $\mathrm{CAV1}^{-/-}$mice could not be attributed to reduced numbers of skin DCs. However, because these experiments were performed in mice that lacked the expression of CAV1 in all cell types, the effects observed for DCs may be attributed to changes in the environment rather than the DCs themselves. Thus, we performed an experiment where CAV1 deficiency was restricted just to DCs. WT and CAV1 $1^{-/-}$BM-DCs were labeled with carboxyfluorescein succinimidyl (CFSE) or Cell Trace Violet (CTV), respectively, mixed at a 1:1 ratio and then injected into the footpad of recipient WT mice. After $24 \mathrm{~h}$, both 
A
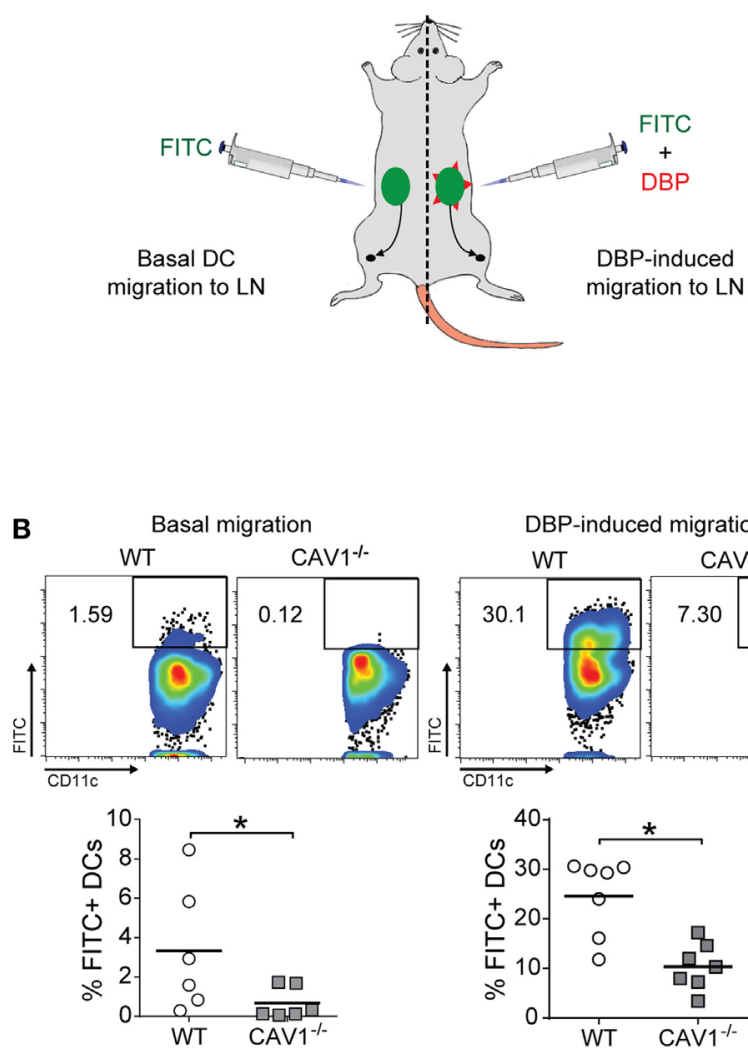

DBP-induced migration
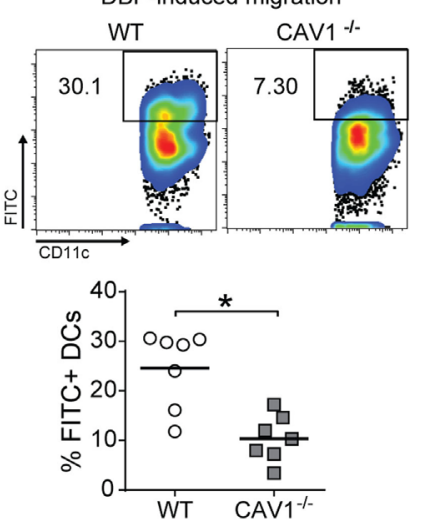
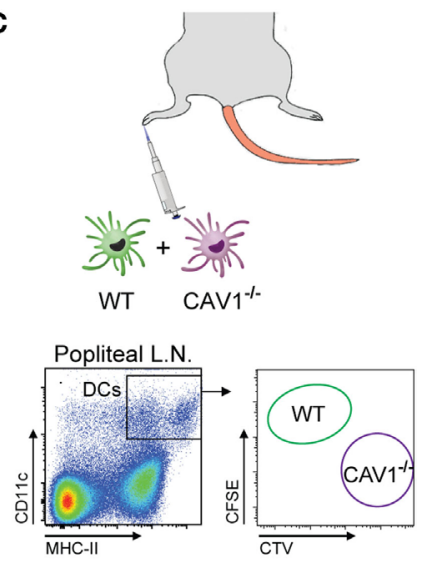

D
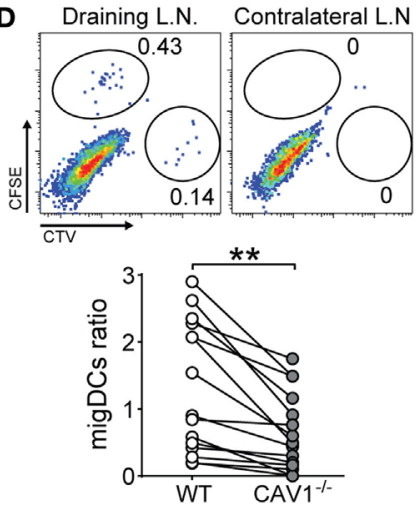

FIGURE 2 | Caveolin-1 (CAV1) favors dendritic cell (DC) trafficking to lymph nodes (LNs) in vivo (A,B). Back skin of wild-type (WT) and CAV1 $1^{-/-}$mice were treated with FITC (left flank) or FITC + dibutyl phthalate (DBP) (right flank), as summarized in (A). (B) After $24 \mathrm{~h}$, the arrival of skin-derived FITC+ DCs to inguinal LNs was evaluated. Representative density plots (top panels) and quantification of FITC+ DCs (bottom panels) under basal or DBP-induced conditions are shown. Each dot represents one animal, and the bar is the mean $\left({ }^{*} p<0.05, n=7\right)$. (C,D) WT and CAV1 ${ }^{-/-}$bone marrow-derived DCs (BM-DCs) were stained with CFSE and Cell Trace Violet (CTV), respectively. Then, WT recipient mice were subcutaneously injected in the right footpad with $5 \times 10^{5}$ cells $(1: 1$ ratio, WT to CAV1-/-) or with PBS as a control (left footpad). The arrival of CFSE (WT) or CTV (CAV1---) BM-DCs to the draining (right) and contralateral (left) popliteal LNs was evaluated $24 \mathrm{~h}$ later. (C) Scheme of footpad injection and gating analysis to analyze transferred BM-DCs. (D) Representative dot plots of DCs in the draining popliteal LNs are shown. Gates showing injected WT and CAV1 ${ }^{-/}$DCs are displayed. The migration index of WT or CAV1 $1^{-/-}$DCs was calculated as $\{[\%$ CTV stained DC in popliteal lymph nodes (PLN)]/(\% CTV stained DC in input)\}/[(\% CFSE WT DC in PLN)/(\% CFSE WT DC in input)]. Data are presented as dot plots with connecting lines per paired samples. ${ }^{*} p<0.01, n=16$ mice, from three independent experiments.

draining and contralateral (control) popliteal LNs were obtained and processed to analyze the presence of transferred WT (CFSEpositive) and CAV1 ${ }^{-/-}$(CTV-positive) DCs by flow cytometry, as depicted in the scheme (Figure 2C, gating strategy similar to Figure S2B in Supplementary Material). As shown (Figure 2D), the frequency of $\mathrm{CAV1}^{-/-}$DCs in the draining popliteal LNs was reduced by nearly $50 \%$ compared with WT DCs. Neither WT nor CAV1 $1^{-/}$DCs were detected in the contralateral LNs. Taken together, these findings indicate that CAV1 intrinsically modulates the migratory behavior of DCs by promoting their trafficking to LNs, which represents a fundamental step to initiate adaptive immune responses.

\section{CAV1 Promotes DC Transmigration}

To shed light on the mechanisms by which CAV1 favors DC trafficking to LNs, we employed in vitro assays that represent the different types of migration that enable DCs to reach secondary lymphoid organs (14): confined unidirectional migration (microchannels), three-dimensional (collagen matrix), and two-dimensional migration (transwell). While microchannels mimic the confined spaces typically present in peripheral tissues (40), collagen matrix migration resembles amoeboid interstitial migration and transwell assays emulate entry to lymphatic vessels and transmigration across lymphatic endothelium. We first evaluated whether CAV1 modulates DC trafficking using fabricated microchannels, as well as in collagen matrix using CCL21 as a chemoattractant. Migration velocities in both assays were similar for WT and $\mathrm{CAV}^{-1-}$ DCs (Figures $3 \mathrm{~A}, \mathbf{B}$ ), indicating that intrinsic DC motility is independent of CAV1. To enter lymphatic vessels, DCs must pass through narrow openings -loose flaps of about 2-3 $\mu \mathrm{m}$ in diameter-present at the beginning of initial lymphatic capillaries (41), in a process that requires 

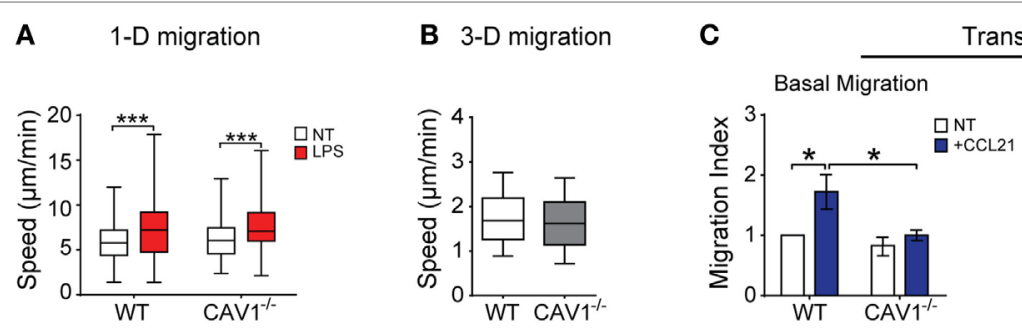

ranswell

D

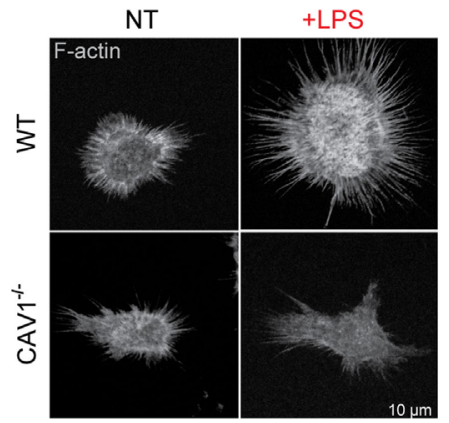

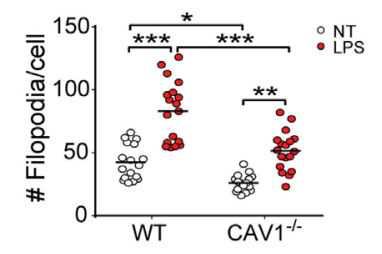

E

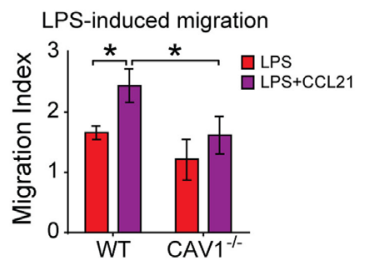

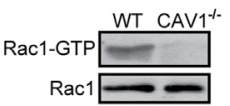

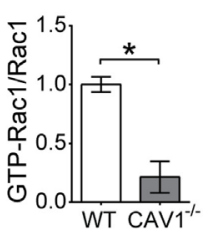

FIGURE 3 | Caveolin-1 (CAV1) promotes dendritic cell (DC) transmigration, actin membrane protrusions, and Rac1 activation. Migration of wild-type (WT) or CAV $1^{-1-}$ bone marrow-derived DCs (BM-DCs) in different in vitro assays. (A) BM-DCs treated or not with LPS (1 $\mu \mathrm{g} / \mathrm{ml}$, for $\left.30 \mathrm{~min}\right)$ were individually tracked in confined microchannels $(4 \mu \mathrm{m})$. After $5-6 \mathrm{~h}$, cell images at different positions along the channels were recorded during 10-12 h (one photo each 2 min) using an automated microscope. The reconstructed movie is analyzed, and the average speed of every cell obtained. In the box plots, the bars include $90 \%$ of the data points, the center corresponds to the median, and the box contains $75 \%$ of the data points. Data from two different experiments, $n=$ WT: 221 , WT + LPS: 153 , CAV1 ${ }^{-1-}: 120, \mathrm{CAV}_{1}^{-/-}$+ LPS: 236 cells $\left({ }^{\star \star \star} p<0.001\right)$. (B) Chemotactic migration of LPS-treated WT or CAV1 ${ }^{-/-}$BM-DCs embedded in a 1\% bovine collagen gel containing a CCL21 gradient. Mean velocity of LPS-DCs depicted as a function of the distance to the CCL21 source. In the box plots, the bars include $90 \%$ of the data points, the center corresponds to the median, and the box contains $75 \%$ of the data points. $n=$ WT: 1,090, CAV $1^{-1-}: 1,169$ tracks, from two independent experiments. (C) DC transwell migration. The bottom side of transwell membranes was coated with fibronectin to avoid losing migratory cell. In the bottom chamber, RPMI medium containing $0.5 \%$ fetal bovine serum with or without CCL21 (20 ng/ml) was added. Then, $2 \times 10^{5}$ of WT or CAV1 ${ }^{-/-}$BM-DCs were seeded in the upper chamber, and migration was evaluated by counting cells on the bottom surface of the membrane. Left panel, immature BM-DC migration after $1 \mathrm{~h}$. Right panel, LPS-matured BM-DC migration after $30 \mathrm{~min}$. The migration index (relative to spontaneous WT DC migration) is shown. Bars are mean \pm SEM $\left({ }^{*} p<0.05, n=3\right)$. (D) In the left panel, representative confocal microscopy images showing F-actin (phalloidin staining) in WT or CAV1 ${ }^{-/-}$BM-DCs treated or not with LPS (100 ng/ml, $24 \mathrm{~h})$. To the right, the quantification of protrusions per cell is shown. Each dot corresponds to one cell, and the black bar represents the mean $\left({ }^{*} p<0.05\right.$, ${ }^{* *} p<0.01$, and ${ }^{* *} p<0.001, n=18$ cells, two experiments). (E) GTP-Rac1 levels were determined in WT and CAV1 ${ }^{-/-}$DCs using pull-down assay followed by Western blot. Representative blots showing the active GTP-bound fraction and total Rac1. The ratio between active and total Rac1 is shown in the plot (densitometry analysis). Data are the mean $\pm \operatorname{SD}\left({ }^{*} p<0.05, n=3\right)$.

direct contact with endothelial cells and matrix (42). Then, DCs transmigrate across lymphatic endothelium to reach the LNs (43). Hence, to determine if CAV1 was involved in facilitating these processes, a transwell migration assay was performed. As shown (Figure 3C, left panel), basal DC transmigration induced by exposure to CCL21 was severely reduced in CAV1 ${ }^{-1-}$ DCs. Moreover, LPS-induced transmigration was also reduced in $\mathrm{CAV}^{-/-}$DCs (Figure 3C, right panel). Taken together, these observations suggested that CAV1 promotes DC trafficking to LNs by increasing transmigration.

It has been suggested that during DC transmigration, the cells actively push open the junction to enter the lymphatic capillary (44). As actin cytoskeleton protrusions could be involved in the junction opening and transmigration across lymphatic endothelium, we evaluated the role of CAV1 in the formation of membrane protrusions. As shown (Figure 3D, left panel), actin microfilament staining using phalloidin revealed a reduced number of actin-based membrane protrusions for immature
$\mathrm{CAV}^{-1-}$ DCs as compared with WT cells. LPS increased significantly membrane protrusions in WT DCs; however, in CAV $1^{-1-}$ DCs almost $40 \%$ fewer projections were detected, suggesting that CAV1 promotes remodeling of the actin cytoskeleton in DCs. Previous reports have implicated the small GTPase Rac1 in actin cytoskeleton remodeling and formation of membrane protrusions in DCs (45), indicating that Racl inhibition decreased DC arrival to LNs (19). Therefore, Racl activity was determined in WT and $C A V 1^{-1-}$ DCs by a pull-down assay that uses a GSTPAK1 fusion protein to immunoprecipitate GTP-bound active Rac1. Then, Racl levels present in the pull-down fraction (Rac1GTP), and total DC lysates were analyzed by Western blotting. As shown (Figure 3E), Racl activation was severely reduced in $\mathrm{CAV}^{-/-}$compared with WT DCs, thereby implicating CAV1 in Racl activation in DCs. Taken together, our results suggest that CAV1 promotes DC migration to the LNs by increasing DC transmigration, likely through Rac1-mediated actin cytoskeleton remodeling. 


\section{CAV1 Enables DCs to Generate Tumor- Protective $\mathrm{CD}^{+}{ }^{+} \mathrm{T}$ Cell Responses}

To assess the potential consequences of CAV1 in promoting DC trafficking to the LNs, we evaluated the ability of DCs to initiate antigen-specific $\mathrm{CD}^{+} \mathrm{T}$ cell responses in vivo (46). Therefore, WT recipient mice were transferred with $\mathrm{WT}$ and $\mathrm{CAV}^{-/-}$DCs pulsed with $\mathrm{OVA}_{257-264}$ peptide to elicit $\mathrm{CD}{ }^{+}$ $\mathrm{T}$ cell responses independently of antigen uptake, processing, and presentation. Seven days later, $\mathrm{OVA}_{257-264}$-specific $\mathrm{CD}^{+}$ $\mathrm{T}$ cell responses were determined in peripheral blood by ex vivo peptide stimulation followed by intracellular IFN- $\gamma$ staining and flow cytometry analysis (see scheme in Figure 4A). As shown (Figure 4B), higher frequencies of IFN- $\gamma$-producing $\mathrm{CD}^{+} \mathrm{T}$ cells in response to $\mathrm{OVA}_{257-264}$ ex vivo stimulation were detected for WT DC-immunized mice compared with the $\mathrm{CAV}^{-/-}$DC-immunized group. To confirm that $\mathrm{CAV} 1^{-/-} \mathrm{DCs}$ elicited reduced $\mathrm{CD}^{+} \mathrm{T}$ cell responses, and not $\mathrm{CD}^{+} \mathrm{T}$ cells with an impaired ability to produce IFN- $\gamma$, the total frequencies of $\mathrm{OVA}_{257-264}$-specific $\mathrm{CD}^{+} \mathrm{T}$ cells were determined by staining with a $\mathrm{H}-2 \mathrm{~Kb} / \mathrm{OVA}_{257-264}$ multimer, which labels $\mathrm{OVA}_{257-264^{-}}$ specific $\mathrm{CD}^{+} \mathrm{T}$ cells regardless of the ability to respond to ex vivo peptide stimulation. As anticipated, reduced frequencies of $\mathrm{H}-2 \mathrm{~Kb} / \mathrm{OVA}_{257-264}$-specific $\mathrm{CD}^{+} \mathrm{T}$ cells were detected in mice immunized with $\mathrm{CAV}^{-/-}$DCs as compared with WT DCs (Figure 4C). Given our results showing that $\mathrm{WT}$ and $\mathrm{CAV} 1^{-1-}$ DCs activate $\mathrm{CD}^{+} \mathrm{T}$ cells equally well when they interact in vitro (Figure S3A in Supplementary Material), these results suggest that the impaired arrival of $\mathrm{CAV}^{-1-} \mathrm{DCs}$ to lymphoid organs leads to reduced $\mathrm{CD} 8^{+} \mathrm{T}$ cell responses.

To validate these results in a functional model that relies on the cytotoxic activity of specific $\mathrm{CD}^{+} \mathrm{T}$ cells in vivo, we performed tumor challenge experiments. To this end, recipient WT mice transferred with $\mathrm{OVA}_{257-264}$-loaded WT or CAV1 ${ }^{-1-} \mathrm{DCs}$ were challenged with ovalbumin-expressing B16 (B16-OVA) melanoma cells, and tumor growth was monitored every 2-3 days (Figure 5A). Significant suppression of tumor growth
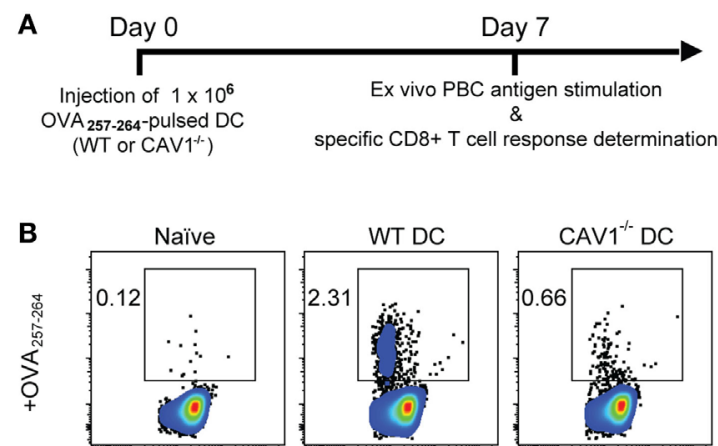

WT DC
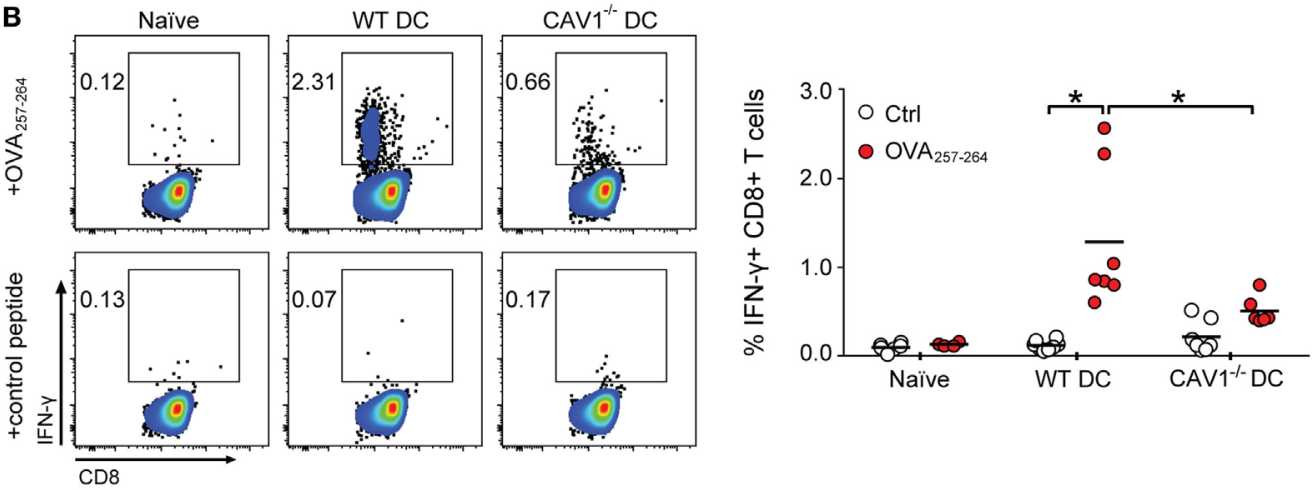

C
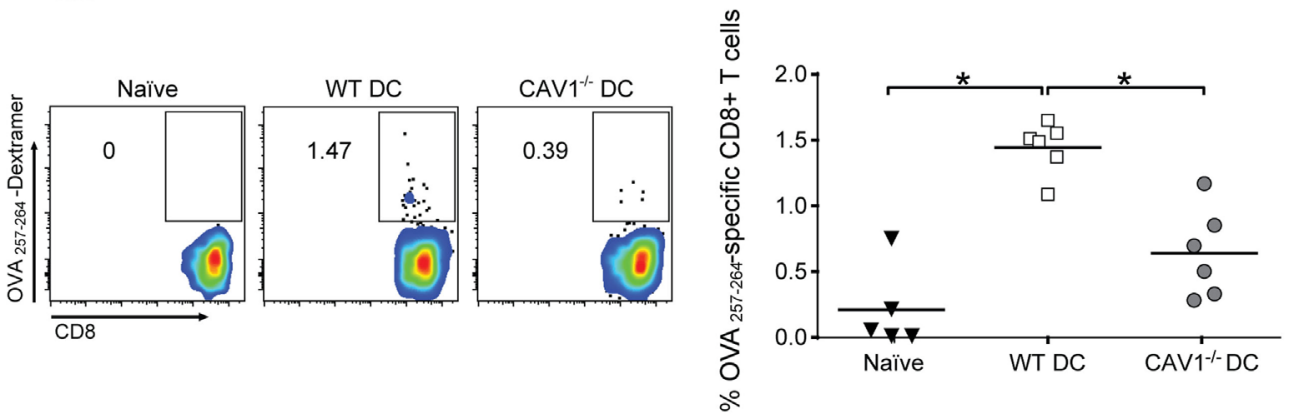

FIGURE 4 | Caveolin-1 (CAV1) promotes the ability of dendritic cells (DCs) to induce antigen-specific CD8 ${ }^{+} \mathrm{T}$ cell responses. (A) Scheme of the experimental procedure. At day $0,1 \times 10^{6} \mathrm{OVA}_{257-265}$-pulsed wild-type $\mathrm{WT}$ ) or CAV1-/- bone marrow-derived DCs (BM-DCs) were transferred to recipient WT mice. After 7 days, blood samples were taken, and CD8 ${ }^{+} \mathrm{T}$ cell responses were analyzed. (B) Cells were stimulated with control (trp2 ${ }_{180-188}$ ) or OVA ${ }_{257-265}$ peptides for 2 h, and then brefeldin A-containing solution (Golgi plug) was added for another $6 \mathrm{~h}$ ( $8 \mathrm{~h}$ total stimulation). Afterward, cells were stained and analyzed by flow cytometry. Representative dot plots of IFN- $\gamma$ expression on gated $\mathrm{CD} 3^{++} \mathrm{CD} 8^{+} \mathrm{T}$ cell population and the percentage of IFN- $\gamma$-producing $\mathrm{CD} 8^{+} \mathrm{T}$ cells are shown. Bars are the mean \pm SEM $\left({ }^{*} p<0.05, n=7\right.$ mice, from two independent experiments). (C) Freshly isolated cells were stained with $\mathrm{H}-2 \mathrm{~Kb} / \mathrm{SIINFEKL}\left(\mathrm{OVA}{ }_{257-265}\right.$ peptide) dextramer to determine antigen-specific CD8 ${ }^{+} \mathrm{T}$ cells. Representative density plots and quantification of frequency of dextramer-positive from totalCD $3^{+} \mathrm{CD} 8^{+}$ T cell population are shown. Data are the mean $\pm \operatorname{SEM}\left({ }^{*} p<0.05, n=5-6\right.$ mice from two independent experiments). 


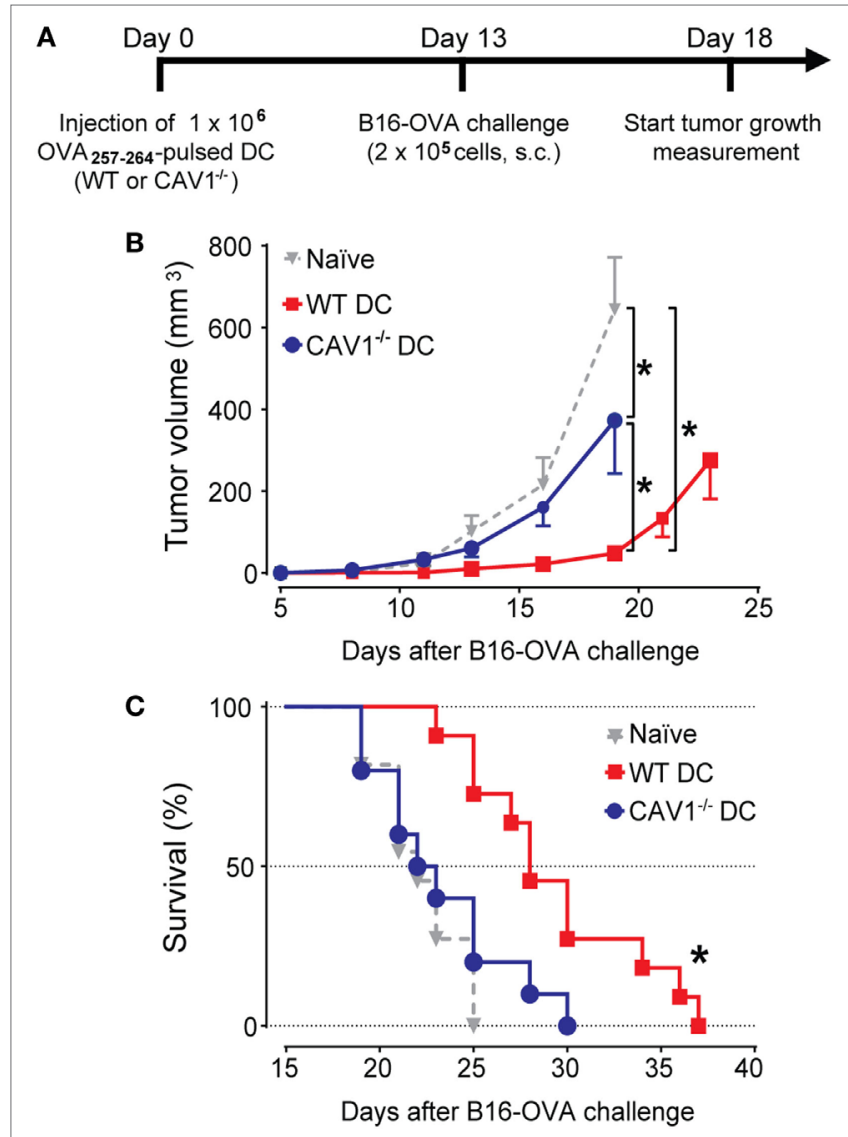

FIGURE 5 | Caveolin-1 (CAV1) promotes dendritic cell (DC)-mediated antitumor protection. (A) Scheme showing experimental procedure. Initially, $1 \times 10^{6} \mathrm{OVA}_{257-265}$-pulsed wild-type (WT) or $\mathrm{CAV}^{-/-} \mathrm{BM}$-DCs were transferred to WT recipient mice. The control group was injected with PBS (vehicle). After 13 days, mice were challenged s.c. with $2 \times 10^{5}$ B16F10-OVA (B16-OVA) cells injected into the right flank. Tumor growth evaluation started 5 days after challenge and was carried out until all the animals were dead. The animals were sacrificed when the length, width, or height surpassed $15 \mathrm{~mm}$. Groups were defined as: control mice group (gray triangles), $\mathrm{OVA}_{257-265}$-loaded WT (WT DCs, red squares), and $\mathrm{OVA}_{257-265}$-loaded $\mathrm{CAV}^{-1-} \mathrm{DCs}$ (CAV1-/- DCs, blue circles). (B) Average tumor growth curves are shown ( ${ }^{*} p<0.05$, $t$-test, $n=8-10$ mice). (C) Survival curves. The mean survival times were as follows: Ctrl group, 22 days; WT DC group, 28 days; CAV1-/- DC group, 22,5 days $\left({ }^{*} p<0.05, n=8-10\right.$ mice, three different experiments).

(Figure 5B) and extended survival (Figure 5C) were observed in mice receiving WT DCs as compared with control-treated (Ctrl) mice. By contrast, tumor suppression and survival were severely compromised in mice that received $\mathrm{CAV}^{-/-} \mathrm{DCs}$. These results indicate that CAV1 promotes the ability of adoptively transferred DCs to initiate tumor-protective $\mathrm{CD} 8^{+} \mathrm{T}$ cell responses. Overall, our data identify a novel role for CAV1 in DC function by promoting DC trafficking to the LNs to efficiently initiate protective cytotoxic $\mathrm{CD}^{+} \mathrm{T}$ cell responses.

\section{DISCUSSION}

In this study, we show that CAV1 expression is upregulated in DCs upon maturation and plays a pivotal role in promoting the trafficking of DCs to LNs, a crucial step to initiate protective adaptive $\mathrm{T}$ cell responses. Furthermore, our data support the notion that CAV1 increases DC trafficking by enhancing transmigration, likely through Rac1-dependent remodeling of actin cytoskeleton. These findings unveil a novel function for CAV1 in DCs with a relevant effect in CTL-mediated responses.

Although it was largely assumed that CAV1 was not expressed in leukocytes, some studies indicated that it may be expressed in the myeloid compartment (30). Previous studies had described the presence of CAV1 in macrophages (47) and DCs (32-34) where the protein played contradictory roles in virus-host interaction. In DCs, CAV1 has been shown to prevent HIV virus infection (35), as well as to dampen host antiviral responses mediated by nitric oxide production (34). However, none of these studies evaluated changes in CAV1 expression upon maturation, its role in migration or initiation of adaptive immune responses. Here, we show that CAV1 is expressed in DCs at steady state, and progressively upregulated upon maturation induced by LPS or TNF- $\alpha$. Moreover, LPS-induced CAV1 upregulation is reinforced at later time points in an autocrine manner by TNF- $\alpha$ (Figure 1; Figure S1 in Supplementary Material). Thus, it seems that TLR4 and TNFR signaling are relevant for CAV1 expression. Given that NF- $\kappa B$ is a master regulator of TLR- and TNF- $\alpha$-dependent DC maturation (48), as well as CAV1 expression in other cell types (49), our data suggest that NF- $\kappa B$ may participate in the control of CAV1 expression in DCs. First, LPS is known to induce NF- $\kappa \mathrm{B}$ activation via TLR4 signaling (50), resulting in TNF- $\alpha$ production. Second, TNF- $\alpha$ activates the TNF receptor that can also lead to NF- $\kappa B$ activation $(51,52)$. Interestingly, TNF- $\alpha$ was described to increase CAV1 transcript levels in human LC (36), a well-known migratory DC subset (53). Taken together, the previously published results and our findings suggest that maturation is linked to CAV1 upregulation in DCs, probably via NF- $\kappa \mathrm{B}$. Therefore, CAV1 upregulation is likely to represent a rather common event in DC biology.

In addition to its well-established role in endocytosis, an emerging role in cell migration has been ascribed to CAV1. However, such a role in immune cells, and particularly in DCs, had not been described yet. Here, we demonstrate that CAV1 promotes migration to draining LNs using two complementary in vivo models. Both endogenous $\mathrm{CAV}^{-1-}$ DCs in knockout mice, as well as $\mathrm{CAV}^{-1-} \mathrm{DCs}$ transferred into WT mice, displayed impaired trafficking to LNs compared with their WT DC counterpart. These in vivo assays show that, even under inflammatory conditions, a major proportion of DCs remain in the tissue and only a few of them are able to find their way through lymph vessels to the draining LNs, inefficiently reaching more distant tissues (6). Hence, our results argue that CAV1 promotes a rate-limiting step of DC migration to the LNs.

To define more precisely the underlying mechanism(s) by which CAV1 favored DC trafficking to LNs, different in vitro migration assays were performed. Our results show that neither amoeboid DC migration nor migration in confined environments were dependent on CAV1 expression (Figures 3A,B). However, results from the transwell assay (Figure 3C), which relies on migration through two-dimensional surfaces and passing through small pores, suggest that CAV1 promotes DC 
transmigration through afferent lymphatic vessels. First, DCs need to enter into lymphatic capillaries through preformed pores present in the basement membrane $(41,54)$, which are about $3 \mu \mathrm{m}$ in diameter (55), but can be stretched to allow DC entry during transmigration $(41,44)$. Thus, in our experiments we used transwells with $8 \mu \mathrm{m}$ size pores to maximize DC transmigration. After entering into the lumen of lymphatic capillaries, DCs need to migrate through the lymphatic endothelium surface following CCL21 gradients toward LNs (42). Hence, our results suggest that $\mathrm{CAV}^{-1-} \mathrm{DCs}$ are unable to appropriately enter and migrate through lymph vessels. Since these processes are dependent on cytoskeleton remodeling, impaired formation of actin-forming protrusions observed in $\mathrm{CAV}^{-/-} \mathrm{DCs}$ may provide an explanation for our results showing reduced in vivo and in vitro migration. Given that Rac1 modulates actin protrusion formation and DC migration $(19,45,56)$, and that Rac1 activity is reduced in CAV1 $1^{-1-} \mathrm{DCs}$, CAV1 may control DC migration by promoting Rac1 activity. It appears that formation of actin protrusions is a major consequence of Rac1 activity, which is linked to DC migration. As described by Benvenuti et al., DC migration in vivo was impaired in Rac1/2-deficient cells, as were rearrangements of actin cytoskeleton after blocking the Rac1 pathway (19). Moreover, CD81 promotes in vitro migration by increasing membrane protrusions via Racl activation (45). Also, CD37 ablation in DCs impairs cell migration in vitro (determined using a transwell assay), reduced dendrite formation in vivo and decreased Rac1 activity (56). Altogether, our results support the notion that CAV1 regulates DC migration by controlling actin cytoskeleton remodeling through activation of Racl and thus promotes efficient DC trafficking to LNs. However, further studies are required to precisely define the underlying mechanism(s).

The potential implications of CAV1 in promoting the ability of DCs to reach the LNs and initiate $\mathrm{CD} 8^{+} \mathrm{T}$ cell responses can be extrapolated to therapeutic interventions. DC-based immunotherapy has been proposed to have the potential to induce immune responses against cancer cells, but clinical trials have met with modest success $(57,58)$. Despite their initial poor clinical benefit, antigen-pulsed DC vaccines were recently shown to increase the breadth and diversity of melanoma neoantigen-specific T cells (59), and overall survival rates $(57,60)$ in stage IV melanoma patients, renewing the interest in employing DCs in clinical treatments. Migration to the LNs appears to represent a key limiting factor that determines the success of DC-based vaccination and the ability to induce T cell immune responses, which lead to favorable clinical outcomes (61). Indeed, DC migration to LNs seems to be a generally inefficient process in DC-based treatments (62), and as a consequence, the generation of specific adaptive immune responses is also suboptimal (63). Hence, the identification of molecular markers and the development of therapeutic strategies that improve DC trafficking need to be considered. Given our results showing that CAV1 promotes DC trafficking and thus the generation of more effective antitumor immune responses, CAV1 status may represent a novel marker for DC function and increasing CAV1 expression in DCs may help to improve DC-based immunotherapies.
In summary, our study demonstrates that CAV1 is upregulated in DCs upon maturation and promotes DC migration to LNs, probably by increasing actin cytoskeleton remodeling via Rac1 activation. While CAV1 expression in DCs is dispensable for $\mathrm{CD}^{+} \mathrm{T}$ cell activation in vitro, it enables DCs to reach the LNs to elicit effective antitumor $\mathrm{CD}^{+} \mathrm{T}$ cell responses in vivo. Therefore, our data identify a novel, hitherto unappreciated function of CAV1 in DCs with important consequences for basic aspects of DC biology that may open up a novel therapeutic window of opportunity to improve DC-based vaccines.

\section{MATERIALS AND METHODS}

\section{Mice}

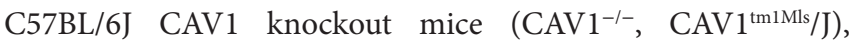
C57BL/6-Tg(TcraTcrb)1100Mjb/J (OT-I), and C57BL/6J WT mice, mice were purchased from Jackson Laboratories (Bar Harbor, ME, USA). Mice were maintained at the SPF animal facility of Fundación Ciencia \& Vida, where breeding and experimental procedures were carried out according to institutional guidelines. This study was carried out in accordance with the recommendations of the Comisión Nacional de Investigación Científica y Tecnológica, CONICYT.

\section{Bone Marrow (BM)- and Spleen-Derived DCs}

Bone marrow-derived DCs were generated from flushed BM suspension from freshly dissected femurs and tibias. Cells were centrifuged for $5 \mathrm{~min}$ at $400 \times g$, treated with Red Blood Cells lysis buffer (BioLegend, San Diego, CA, USA) for $5 \mathrm{~min}$, washed with PBS, centrifuged again and then cultured for 6 days in supplemented medium (RPMI medium; Hyclone, Logan, UT, USA) containing 10\% fetal bovine serum (FBS, Hyclone, Logan, UT, USA), $20 \mathrm{ng} / \mathrm{ml}$ granulocyte-macrophage colony stimulating factor (BioLegend, San Diego, CA, USA), 1\% non-essential amino acids, $1 \%$ L-glutamine, $1 \%$ penicillin-streptomycin, and $0.1 \%$ $\beta$-mercaptoethanol (Invitrogen, Carlsbad, CA, USA). Sp-DCs were purified from freshly isolated spleen using the EasySep Mouse CD11c Positive Selection Kit (StemCell, Vancouver, $\mathrm{BC}$, Canada) according to the manufacturer's instructions and then cultured in supplemented RPMI medium. Freshly isolated Sp-DCs or BM-DCs at day 6 were treated with LPS $100 \mathrm{ng} / \mathrm{mL}$ (S. typhimurium, L6143 Sigma-Aldrich, St. Louis, MO, USA) or TNF- $\alpha$ (20 ng/ml, BioLegend, San Diego, CA, USA) for different times as specified in each figure. In some experiments, BM-DCs were treated with LPS $(100 \mathrm{ng} / \mathrm{ml})$ together with anti-TNF- $\alpha$ blocking antibody $(1 \mu \mathrm{g} / \mathrm{ml}$, BioLegend, San Diego, CA, USA, clone MP6-XT22).

\section{Western Blotting}

Dendritic cells $\left(2 \times 10^{6}\right)$ were lysed in RIPA buffer $(50 \mathrm{nM}$ Tris-HCl, $\mathrm{pH} 7.4,1 \%$ Triton-X, $0.5 \%$ Na-deoxycholate, $0.1 \%$ SDS, $150 \mathrm{mM} \mathrm{NaCl}, 2 \mathrm{mM}$ EDTA, and $50 \mathrm{mM} \mathrm{NaF}$ ) containing a protease inhibitor cocktail (cOmplete EDTA-free Protease Inhibitor Cocktail, Roche, Basel, Switzerland). Cell lysates were incubated for $15 \mathrm{~min}$ on ice and then centrifuged at $15,000 \times g$ 
for $10 \mathrm{~min}$ at $4^{\circ} \mathrm{C}$ to obtain the supernatant. Protein concentrations were determined using the bicinchoninic acid protein assay kit (Thermo Scientific, Waltham, MA, USA) according to the manufacturer's instructions. Samples' concentration was normalized, and equal amount of samples were mixed with $6 \times$ SDS-polyacrylamide gel electrophoresis (SDS-PAGE) loading buffer [360 mM Tris- $\mathrm{HCl}(\mathrm{pH}=6,8), 60 \%$ glycerol, $12 \%$ SDS, $10 \%$ 2-mercaptoethanol, $0.03 \%$ Bromophenol Blue] heated to $95^{\circ} \mathrm{C}$ for $5 \mathrm{~min}$ and stored at $-20^{\circ} \mathrm{C}$ until used. Then, $40 \mu \mathrm{g}$ protein per sample was separated by SDS-PAGE (12\% gel) at $120 \mathrm{~V}$ for $100 \mathrm{~min}$ in TGS buffer (25 mM Tris, $200 \mathrm{mM}$ glycine, and $0.1 \%$ SDS) and then transferred to nitrocellulose membranes using a wet transfer Mini-Trans Blot system (Bio Rad, Hercules, CA, USA) at $400 \mathrm{~mA}$ for $90 \mathrm{~min}$ at $4^{\circ} \mathrm{C}$ in transference buffer (25 mM Tris, $200 \mathrm{mM}$ glycine, $0.1 \%$ SDS, and $20 \% \mathrm{MeOH}$ ). The membranes were washed three times with PBS-Tween $0.05 \%$ and subsequently incubated with blocking solution (3\% nonfat dry milk in PBS-Tween 0.05\%) at room temperature for $1 \mathrm{~h}$. Primary antibodies were incubated overnight at $4^{\circ} \mathrm{C}$ diluted in blocking solution: anti-CAV1 (1:4,000, BD Transduction Laboratories, Franklin Lakes, NJ, USA), anti-actin (1:5,000, Sigma-Aldrich, St. Louis, MO, USA), anti-GAPDH (1:5,000, Cell Signaling, Danvers, MA, USA), and anti-Rac1 (1:4,000, BD Transduction Laboratories, Franklin Lakes, NJ, USA). Then, the membranes were washed and incubated with anti-rabbit HRPlinked secondary antibody (1:2,000, Sigma-Aldrich, St. Louis, $\mathrm{MO}$, USA) for $1 \mathrm{~h}$ at room temperature in blocking solution. Chemiluminescence was detected using the Supersignal West Pico kit (Thermo Scientific, Waltham, MA, USA) followed by exposure to photographic films (CL-XPosure Films, Thermo Scientific, Waltham, MA, USA). The digitized images were used for densitometry analysis using ImageJ software (NIH, Bethesda, MD, USA). CAV1 levels were normalized by actin or GAPDH levels, depending on the experiment.

\section{FITC Painting Assay}

This procedure was performed as previously described (38). The back skin of mice was shaved and then inoculated on the right lateral flank with $12 \mu \mathrm{l}$ of a $1 \%$ FITC solution (Isomer 1, Sigma-Aldrich, St. Louis, MO, USA) prepared in acetone (control). The left flank was inoculated with $12 \mu \mathrm{l}$ of a $1 \%$ FITC solution prepared in acetone plus DBP $(1: 1)$ to induce skin irritation. After 20-22 h, mice were sacrificed, and draining inguinal LNs were obtained, and single cell suspensions were prepared using a solution containing collagenase IV $(5 \mathrm{mg} / \mathrm{ml}$, Gibco, Thermo Scientific, Waltham, MA, USA) and DNAse I ( $5 \mathrm{mg} / \mathrm{ml}$, AppliChem, Maryland Heights, MO, USA) in RPMI supplemented with $0.5 \% \mathrm{FBS}$ for $45 \mathrm{~min}$ at $37^{\circ} \mathrm{C}$ in a shaker bath. Then, the cells were stained with either anti-CD11c PE/ Cy7-conjugated (clone N418, BioLegend, San Diego, CA, USA), anti-MHC-II APC/Cy7-congujated (clone M5/114.15.2, BioLegend, San Diego, CA, USA), or Zombie Aqua (BioLegend, San Diego, CA, USA) for $30 \mathrm{~min}$ and then fixed with a $2 \%$ paraformaldehyde solution and then evaluated by flow cytometry.

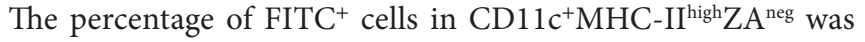
determined.

\section{Migration to Popliteal LNs}

Bone marrow-derived DCs from WT or CAV1 $1^{-/-}$mice were stained with carboxyfluorescein succinimidyl ester (CFSE, BD Biosciences, Franklin Lakes, NJ, USA) or CTV (BD Biosciences, Franklin Lakes, NJ, USA), respectively, according to protocols provided by the manufacturer. Then, labeled WT and CAV1 $1^{-1-}$ BM-DCs were mixed at a 1:1 ratio in PBS and $5 \times 10^{5}$ total BM-DCs in $40 \mu \mathrm{l}$ were injected into the footpad of the left lower extremity (footpad) of recipient WT mice. The exact percentage of WT and CAV1 $1^{-1-}$ actually injected (input DC) in was determined by FACS as $\mathrm{CTV}^{+}$or $\mathrm{CFSE}^{+}$cells in the mix and used to calculate "migration index." After $24 \mathrm{~h}$ postinjection, draining popliteal lymph nodes of each limb were obtained and digested as described earlier. Single cell suspensions were labeled with anti-CD11c conjugated with APC/Cy7 (clone N418, BioLegend, San Diego, CA, USA) and anti-MHC-II conjugated with PerCP (clone M5/114.15.2, BioLegend, San Diego, CA, USA) and then analyzed by flow cytometry. The number of cells that migrated (migration index) was calculated as follows:

migration index $=\left\{\frac{\% \text { stained DC in PLN } / \% \text { stained DC in input }}{\% \text { WT DC in PLN } \% \text { WT DC in input }}\right\}$.

The mean of the values for control condition was defined as 1 for further relativization.

\section{Transwell Assay}

Transwell assays were performed in Boyden chambers (Transwell Costar, Thermo Scientific, Waltham, MA, USA, $6.5 \mathrm{~mm}$ diameter, $8 \mu \mathrm{M}$ pore). The outer side of the membrane was coated with $2 \mu \mathrm{g} / \mathrm{ml}$ fibronectin for $18 \mathrm{~h}$ at $4^{\circ} \mathrm{C}$. BM-DCs $\left(2 \times 10^{4}\right.$ in $200 \mu \mathrm{l}$ of RPMI medium containing $0.5 \%$ FBS) were seeded in the upper chamber, and the same medium containing CCL21 $(20 \mathrm{ng} / \mathrm{ml}$, BioLegend, San Diego, CA, USA) was added to the lower chamber to induce migration. After $1 \mathrm{~h}$, the membranes were removed, washed, and stained with a solution containing $0.1 \%$ crystal violet in $2 \%$ ethanol and cells that migrated and adhered to the lower membrane surface were photographed under a microscope and counted. The migration index was calculated as follows:

migration index $=$ number of migrated DC /number of migrated WT DC in control.

The average of control condition was defined as 1 for further relativization.

\section{Migration in Microchannels}

Bone marrow-derived DCs were prepared for migration in microchannels as previously described (64), and the experiments were conducted as published before (64). In brief, the cells were introduced into the fibronectin $(10 \mu \mathrm{g} / \mathrm{ml})$-coated microchannels, without any mechanical or chemical stimulation. To assess the effect of LPS on DC migration in microchannels, BM-DCs were treated or not with LPS $(1 \mu \mathrm{g} / \mathrm{ml})$ for $30 \mathrm{~min}$, followed by three rinses to wash out the LPS. After 5-6 h of LPS treatment, cells' phase contrast images were recorded during $10-12 \mathrm{~h}$ at 
various positions in the chambers and with 2 min time lapses (to record multiple fields at low resolution for statistics) using an automated microscope (Nikon ECLIPSE TE1000-E and Olympus X71, with a Marzhauser motorized stage and an HQ2 Roper camera) equipped with an environmental chamber to control temperature, humidity, and $\mathrm{CO}_{2}$ (Life Imaging Services). The analysis of migration parameters was performed as described previously (64).

\section{Migration in Collagen Gels}

Mature DCs were obtained by treating immature DCs with LPS $(100 \mathrm{ng} / \mathrm{ml})$ for $30 \mathrm{~min}$ and washing three times with supplemented medium. For collagen preparation, $120 \mu \mathrm{l}$ of DCs (stock at $2 \times 10^{6} \mathrm{million} / \mathrm{ml}$ ) were carefully mixed with $205 \mu \mathrm{l}$ of bovine type I collagen (stock $6 \mathrm{mg} / \mathrm{ml}$ ) (Advanced BioMatrix, San Diego, CA, USA) and $13 \mu \mathrm{l}$ of $\mathrm{NaHCO}_{3}$ (stock 7.5\%) (Sigma-Aldrich, St. Louis, MO, USA). All solutions were previously equilibrated at $4^{\circ} \mathrm{C}$. Then, the sample was loaded in a custom-made poly(dimethylsiloxane) (PDMS) "collagen chamber". The chip was then incubated at $37^{\circ} \mathrm{C}$ for $30 \mathrm{~min}$ to allow collagen polymerization. To generate the CCL21 gradient, BM-DC medium containing $200 \mathrm{ng} / \mathrm{ml}$ of CCL21 (R\&D Systems, Minneapolis, MN, USA) was added outside of the chamber. The cells were imaged by phase contrast at a frequency of 1 image every 2 min using a $10 \times$ objective. Images were processed to visualize cells by subtraction of the mean image of the whole movie at every time point, to obtain white objects on a dark background. Then cells were tracked as previously described (65).

\section{Confocal Microscopy and Image Acquisition}

Bone marrow cells $\left(2 \times 10^{5}\right)$ were cultured in 12-well plates containing $10 \mathrm{~mm}$ coverslips and differentiated into BM-DCs for 6 days using GM-CSF, as described. Cells were stimulated or not with LPS $(100 \mathrm{ng} / \mathrm{ml})$ for $24 \mathrm{~h}$, washed three times with cold PBS and then fixed with $4 \%$ paraformaldehyde for $10 \mathrm{~min}$ at $4^{\circ} \mathrm{C}$, washed again, permeabilized using Triton X-100 0.2\% in PBS for $10 \mathrm{~min}$, and then blocked with a PBS-BSA 3\% solution for $1 \mathrm{~h}$ at room temperature. The cells were incubated with anti-CAV1 antibody (1:200) overnight at $4^{\circ} \mathrm{C}$, washed three times with PBS and then incubated $2 \mathrm{~h}$ at room temperature in the dark with anti-rabbit second antibody conjugated with Alexa Fluor 488 (Thermo Scientific, Waltham, MA, USA) in a 1: 500 dilution together with $500 \mathrm{nM}$ phalloidin rhodamine (Sigma-Aldrich, St. Louis, MO, USA) and $100 \mathrm{nM} \mathrm{4',6-diamidino-2-phenylindole}$ (Sigma-Aldrich, St. Louis, MO, USA). Coverslips were washed and mounted on microscope slides with Mowiol 4-88 (SigmaAldrich, St. Louis, MO, USA), and samples were visualized with an Olympus IX81 DSU microscope and analyzed with ImageJ software. Membrane protrusions were counted manually for at least 10 cells per condition in two experiments.

\section{Rac1-GTP Pull-down Assay}

Rac1-GTP pull-down assays were performed as described previously (27). Briefly, cells were lysed in a buffer containing $25 \mathrm{mM}$
HEPES (pH 7.4), 100 mM NaCl, 5 mM MgCl , 1\% NP-40, 10\% glycerol, $1 \mathrm{mM}$ dithiothreitol, and protease inhibitors. Extracts were incubated for $5 \mathrm{~min}$ on ice and clarified by centrifugation $\left(10,000 \times g, 1 \mathrm{~min}, 4^{\circ} \mathrm{C}\right)$. Supernatants were used for pull-down assays with $50 \mu \mathrm{g}$ of GST-PAK1 pre-coated GSH beads per condition. Beads were incubated with supernatant for $15 \mathrm{~min}$ at $4^{\circ} \mathrm{C}$ in a rotating shaker. Thereafter, beads were collected, washed with lysis buffer containing $0.01 \%$ NP-40. Samples were separated by SDS-PAGE ( $12 \%$ acrylamide) and analyzed by Western blotting using anti-Rac1 (1:1,000) antibody from Transduction Laboratories (Lexington, KY, USA).

\section{T Cell Proliferation Assay}

Wild-type or $\mathrm{CAV}^{-/-}$DCs were pulsed with different amounts of OVA $_{257-264}$ peptide $(10,1$, or $0.1 \mu \mathrm{g} / \mathrm{ml})$ for $4 \mathrm{~h}$ and then washed. $5 \times 10^{3}$ DCs were cocultured with $1 \times 10^{5}$ CFSE-labeled (as described before) $\mathrm{CD}^{+} \mathrm{T}$ cells purified from the spleen of OT-I mice using the EasySep $\mathrm{CD}^{+} \mathrm{T}$ Cell Enrichment Kit (StemCell, Vancouver, BC, Canada). Proliferation of CD8 ${ }^{+} \mathrm{T}$ cells was evaluated by assessing CFSE dilution by flow cytometry in the $\mathrm{CD}^{+} \mathrm{CD}^{+} \mathrm{V} 2^{+}$population using PerCP-conjugated antiCD3 (clone 145-1211, BioLegend, San Diego, CA, USA), APC-conjugated anti-CD8 (clone 53-6.7, BioLegend, San Diego, $\mathrm{CA}, \mathrm{USA}$ ), and Pacific Blue-conjugated anti-V $\alpha 2$ (clone B20.1, BioLegend, San Diego, CA, USA).

\section{Staining and Cytokine Secretion}

Wild-type or $\mathrm{CAV}^{-/-}$DCs were stimulated or not with LPS $(100 \mathrm{ng} / \mathrm{ml})$ for $24 \mathrm{~h}$ and then stained for $30 \mathrm{~min}$ at $4^{\circ} \mathrm{C}$ in $50 \mu \mathrm{l}$ of PBS-BSA $2 \%$ solution with the following antibodies (all from BioLegend, San Diego, CA, USA): anti-CD11c APC-conjugated (clone N418, dilution 1:250), anti-CD40 PE-conjugated (clone $3 / 23$, dilution 1:125), anti-CD80 FITC-conjugated (clone 1610A1, dilution 1:250), anti-CD86 PE/Cy7-conjugated (clone GL-1, dilution 1:250), anti-CD38 Alexa Fluor 488-conjugated (clone 90, dilution 1:200), anti-PD-L1 PE/Cy7-conjugated (clone 10F.9G2, dilution 1:250), anti CD14 PE-conjugated (clone Sa142, dilution 1:100), anti-CCR7 Brilliant Violet 421-conjugated (clone 4B12, dilution 1:100), anti-MHC-I PE-conjugated (clone M1/42, dilution 1:125), and anti-MHC-II PerCP-conjugated (clone M5/114.15.2, dilution 1:250). Zombie Aqua (BioLegend) was used to determine cell viability (1:500 dilution). Non-specific binding was blocked by mouse Fc receptor blocking (BioLegend, clone 93, dilution 1:100). Then, the cells were washed and fixed with $2 \%$ paraformaldehyde PBS and analyzed by flow cytometry. Approximately 10,000 events in the $\mathrm{MHC}-\mathrm{II}^{+} \mathrm{CD} 11^{+}$gate were recorded per sample. Samples were acquired in a FACSCanto II cytometer (BD Bioscience), and the data analyzed using FlowJo version X (Tree Star Inc.). If correspond, the average of control condition was defined as 1 for further relativization. For the ELISA experiments, the supernatants of stimulated DCs were used to determine secretion of IL-6 (capture antibody: clone MP5-20F3; detection antibody: clone MP5-32C11); IL-12 (capture antibody: clone $\mathrm{C} 18.2$; detection antibody: clone $\mathrm{C} 17.8)$, and TNF- $\alpha$ (capture antibody: clone MP6-XT22; detection antibody: C19.2), following the manufacturer's instructions (BioLegend, San Diego, CA, USA). 


\section{Immunization and Evaluation of CD8 ${ }^{+} \mathbf{T}$ Cell Responses}

Wild-type or $\mathrm{CAV}^{-/-}$DCs pulsed with $\mathrm{OVA}_{257-264}$ peptide $(10 \mu \mathrm{g} / \mathrm{ml}$ for $4 \mathrm{~h})$ were washed three times with cold PBS and then injected intravenous (i.v., $10^{6}$ cells) into recipient mice. PBS was used as vehicle control. Seven days after immunization, blood samples were obtained, and red blood cells were removed by using Red Blood Cells lysis buffer as described before. The samples were split in two fractions: one used for intracellular staining and the second for multimer staining. For intracellular cytokine staining, the cells were washed with PBS and stimulated ex vivo with $\mathrm{OVA}_{257-264}$ peptide $(2.5 \mu \mathrm{g} / \mathrm{ml})$ in supplemented RPMI. After $2 \mathrm{~h}$, Golgi plug (brefeldin A) was added $(1 \mu \mathrm{l} / \mathrm{ml}, \mathrm{BD}$ Biosciences, Franklin Lakes, NJ, USA) for the last $6 \mathrm{~h}$. Cells were first incubated with labeled with Fc receptor blocking (BioLegend, clone 93) and then labeled with the following antibodies (all from BioLegend, San Diego, CA, USA): PerCP-conjugated anti-CD3 (clone 145-1211), APC/Cy7-conjugated anti-CD8 (clone 53-6.7), plus Zombie aqua (as viability dye). Then cells were fixed and permeabilized using BD Cytofix/Cytoperm Kit (BD Biosciences, Franklin Lakes, NJ, USA) according to the manufacturer's instructions. Intracellular staining was performed using PE-conjugated anti-INF- $\gamma$ (clone XMG1.2) and APC-conjugated anti-TNF- $\alpha$ (clone MP6-XT22) antibodies. For multimer staining, cells were incubated with $\mathrm{Fc}$ receptor blocking and labeled PerCPconjugated anti-CD3 (clone 145-1211), APC/Cy7-conjugated anti-CD8 (clone 53-6.7), Zombie aqua (as described earlier), and APC-conjugated MHC class I $\mathrm{H}-2 \mathrm{~Kb}$ dextramer loaded with $\mathrm{OVA}_{257-264}$ peptide (SIINFEKL), according to the manufacturer's instructions (Immudex, Copenhagen, Denmark).

\section{Tumor Challenge}

After 12 days from DC immunization, mice were injected subcutaneously with B16F10-OVA tumor cells $\left(2.5 \times 10^{5}\right.$ cells in PBS, $95 \%>$ viability, $60-80 \%$ confluence at harvesting day). The evaluation of tumor size (length, width, and height) started 5 days after challenge, and the volume was calculated as (length $\times$ width $\times$ height)/2. Mice were sacrificed if one of the measures exceeded $15 \mathrm{~mm}$, to avoid unnecessary suffering. The tumor size was plotted against time post challenge, and the animal survival was plotted as Kaplan-Meier survival curve.

\section{Statistical Analysis}

Experimental data are presented as the mean \pm SD or mean \pm SEM of the number of experiments indicated as " $n$ " or as representative results of at least two independent experiments. For determination of significance, data sets of two conditions were analyzed using Student's $t$-test and Turkey's post hoc analysis; for multiple data sets, one-way analysis of variance was used (ANOVA) and

\section{REFERENCES}

1. Banchereau J, Steinman RM. Dendritic cells and the control of immunity. Nature (1998) 392(6673):245-52. doi:10.1038/32588

2. Banchereau J, Briere F, Caux C, Davoust J, Lebecque S, Liu YJ, et al. Immunobiology of dendritic cells. Annu Rev Immunol (2000) 18:767-811. doi:10.1146/annurev.immunol.18.1.767
Bonferroni's post hoc applied. Tumor growth was compared using the Wilcoxon rank sum test, and survival curves (Kaplan-Meier survival curve showing tumor-free survival) were compared using the Mantel-Cox test. A $p$ value $<0.05$ was considered a statistically significant difference between the data compared $\left({ }^{* *} p \leq 0.001 ;{ }^{* *} p \leq 0.01\right.$, and $\left.{ }^{*} p \leq 0.05\right)$.

\section{ETHICS STATEMENT}

This study was carried out in accordance with the recommendations of the "Guidelines for the welfare and use of animals in cancer research, Committee of the National Cancer Research Institute". The protocol was approved by the "Committee of Bioethics and Biosafety" from Fundación Ciencia \& Vida.

\section{AUTHOR CONTRIBUTIONS}

$\mathrm{AL}, \mathrm{CO}$, and $\mathrm{AQ}$ designed research; CO, SC-G, FG-C, PV, HM, ND-V, and JD performed research; CO, SC-G, FG-C, and PV prepared figures: $\mathrm{CO}, \mathrm{SC}-\mathrm{G}, \mathrm{FG}-\mathrm{C}, \mathrm{PV}, \mathrm{AQ}$, and $\mathrm{AL}$ analyzed and interpreted the data; AL-D, RP, and FS-O contributed tools and discussed results; and $\mathrm{CO}, \mathrm{AQ}$, and $\mathrm{AL}$ wrote the paper.

\section{ACKNOWLEDGMENTS}

The authors greatly acknowledge the Cell and Tissue Imaging facility (PICT-IBiSA), Institut Curie, member of the French National Research Infrastructure France-BioImaging (ANR10-INBS-04). The authors also thank Dr. Fabiola Osorio (Universidad de Chile) for facilitating antibody reagents.

\section{FUNDING}

This work was funded by grants CONICYT PFB-16 (to AL), CONICYT-FONDAP 15130011 and Anillo Project ACT1111 (to AQ) from "Comisión Nacional de Investigación Científica y TecnológicadeChile"; FONDECYT11171703(to AL),FONDECYT 1170093 (to RP), and FONDECYT 1130250, 1170925 (to AQ) from "Fondo Nacional de Desarrollo Científico y Tecnológico de Chile"; and P09/016-F (to FS-O and AL) from the Millennium Science Initiative. $\mathrm{CO}, \mathrm{FG}-\mathrm{C}, \mathrm{ND}-\mathrm{V}$, and JD were supported by CONICYT PhD scholarships. HDM was supported by the Fondation pour la Recherche Médicale fellowship SPF20140129479.

\section{SUPPLEMENTARY MATERIAL}

The Supplementary Material for this article can be found online at http://www.frontiersin.org/articles/10.3389/fimmu.2017.01794/ full\#supplementary-material.

3. Randolph GJ, Angeli V, Swartz MA. Dendritic-cell trafficking to lymph nodes through lymphatic vessels. Nat Rev Immunol (2005) 5(8):617-28. doi:10.1038/ nri1670

4. Worbs T, Hammerschmidt SI, Forster R. Dendritic cell migration in health and disease. Nat Rev Immunol (2017) 17(1):30-48. doi:10.1038/nri.2016.116

5. Forster R, Schubel A, Breitfeld D, Kremmer E, Renner-Muller I, Wolf E, et al. CCR7 coordinates the primary immune response by establishing functional 
microenvironments in secondary lymphoid organs. Cell (1999) 99(1):23-33. doi:10.1016/S0092-8674(00)80059-8

6. MartIn-Fontecha A, Sebastiani S, Hopken UE, Uguccioni M, Lipp M, Lanzavecchia A, et al. Regulation of dendritic cell migration to the draining lymph node: impact on T lymphocyte traffic and priming. J Exp Med (2003) 198(4):615-21. doi:10.1084/jem.20030448

7. Schumann K, Lammermann T, Bruckner M, Legler DF, Polleux J, Spatz JP, et al. Immobilized chemokine fields and soluble chemokine gradients cooperatively shape migration patterns of dendritic cells. Immunity (2010) 32(5):703-13. doi:10.1016/j.immuni.2010.04.017

8. Schwarz J, Bierbaum V, Vaahtomeri K, Hauschild R, Brown M, de Vries I, et al. Dendritic cells interpret haptotactic chemokine gradients in a manner governed by signal-to-noise ratio and dependent on GRK6. Curr Biol (2017) 27(9):1314-25. doi:10.1016/j.cub.2017.04.004

9. Alvarez D, Vollmann EH, von Andrian UH. Mechanisms and consequences of dendritic cell migration. Immunity (2008) 29(3):325-42. doi:10.1016/j. immuni.2008.08.006

10. Xu H, Guan H, Zu G, Bullard D, Hanson J, Slater M, et al. The role of ICAM-1 molecule in the migration of Langerhans cells in the skin and regional lymph node. Eur J Immunol (2001) 31(10):3085-93. doi:10.1002/1521-4141 (2001010)31:10<3085::AID-IMMU3085>3.0.CO;2-B

11. Cera MR, Del Prete A, Vecchi A, Corada M, Martin-Padura I, Motoike T, et al. Increased DC trafficking to lymph nodes and contact hypersensitivity in junctional adhesion molecule-A-deficient mice. JClin Invest (2004) 114(5):729-38. doi:10.1172/JCI21231

12. Takamatsu H, Takegahara N, Nakagawa Y, Tomura M, Taniguchi M, Friedel RH, et al. Semaphorins guide the entry of dendritic cells into the lymphatics by activating myosin II. Nat Immunol (2010) 11(7):594-600. doi:10.1038/ ni. 1885

13. Teijeira A, Russo E, Halin C. Taking the lymphatic route: dendritic cell migration to draining lymph nodes. Semin Immunopathol (2014) 36(2):261-74. doi:10.1007/s00281-013-0410-8

14. Heuze ML, Vargas P, Chabaud M, Le Berre M, Liu YJ, Collin O, et al. Migration of dendritic cells: physical principles, molecular mechanisms, and functional implications. Immunol Rev (2013) 256(1):240-54. doi:10.1111/ imr. 12108

15. Ulvmar MH, Werth K, Braun A, Kelay P, Hub E, Eller K, et al. The atypical chemokine receptor CCRL1 shapes functional CCL21 gradients in lymph nodes. Nat Immunol (2014) 15(7):623-30. doi:10.1038/ni.2889

16. Maiuri P, Rupprecht JF, Wieser S, Ruprecht V, Benichou O, Carpi N, et al. Actin flows mediate a universal coupling between cell speed and cell persistence. Cell (2015) 161(2):374-86. doi:10.1016/j.cell.2015.01.056

17. Xu Y, Pektor S, Balkow S, Hemkemeyer SA, Liu Z, Grobe K, et al. Dendritic cell motility and $\mathrm{T}$ cell activation requires regulation of Rho-cofilin signaling by the Rho-GTPase activating protein myosin IXb. J Immunol (2014) 192(8):3559-68. doi:10.4049/jimmunol.1300695

18. Lammermann T, Renkawitz J, Wu X, Hirsch K, Brakebusch C, Sixt M. Cdc42-dependent leading edge coordination is essential for interstitial dendritic cell migration. Blood (2009) 113(23):5703-10. doi:10.1182/blood2008-11-191882

19. Benvenuti F, Hugues S, Walmsley M, Ruf S, Fetler L, Popoff M, et al. Requirement of Rac1 and Rac2 expression by mature dendritic cells for T cell priming. Science (2004) 305(5687):1150-3. doi:10.1126/science.1099159

20. Parton RG, Hanzal-Bayer M, Hancock JF. Biogenesis of caveolae: a structural model for caveolin-induced domain formation. J Cell Sci (2006) 119 (Pt 5):787-96. doi:10.1242/jcs.02853

21. Parat MO, Anand-Apte B, Fox PL. Differential caveolin-1 polarization in endothelial cells during migration in two and three dimensions. Mol Biol Cell (2003) 14(8):3156-68. doi:10.1091/mbc.E02-11-0761

22. Sotgia F, Martinez-Outschoorn UE, Howell A, Pestell RG, Pavlides S, Lisanti MP. Caveolin-1 and cancer metabolism in the tumor microenvironment: markers, models, and mechanisms. Annu Rev Pathol (2012) 7:423-67. doi:10.1146/ annurev-pathol-011811-120856

23. Nunez-Wehinger S, Ortiz RJ, Diaz N, Diaz J, Lobos-Gonzalez L, Quest AF. Caveolin-1 in cell migration and metastasis. Curr Mol Med (2014) 14(2): 255-74. doi:10.2174/1566524014666140128112827

24. Wang Z, Wang N, Liu P, Peng F, Tang H, Chen Q, et al. Caveolin-1, a stressrelated oncotarget, in drug resistance. Oncotarget (2015) 6(35):37135-50. doi:10.18632/oncotarget.5789
25. Grande-Garcia A, Echarri A, de Rooij J, Alderson NB, Waterman-Storer CM, Valdivielso JM, et al. Caveolin-1 regulates cell polarization and directional migration through Src kinase and Rho GTPases. J Cell Biol (2007) 177(4): 683-94. doi:10.1083/jcb.200701006

26. Urra H, Torres VA, Ortiz RJ, Lobos L, Diaz MI, Diaz N, et al. Caveolin-1enhanced motility and focal adhesion turnover require tyrosine-14 but not accumulation to the rear in metastatic cancer cells. PLoS One (2012) 7(4):e33085. doi:10.1371/journal.pone.0033085

27. Diaz J, Mendoza P, Ortiz R, Diaz N, Leyton L, Stupack D, et al. Rab5 is required in metastatic cancer cells for caveolin-1-enhanced Racl activation, migration and invasion. J Cell Sci (2014) 127(Pt 11):2401-6. doi:10.1242/ jcs. 141689

28. Lobos-Gonzalez L, Aguilar L, Diaz J, Diaz N, Urra H, Torres VA, et al. E-cadherin determines caveolin-1 tumor suppression or metastasis enhancing function in melanoma cells. Pigment Cell Melanoma Res (2013) 26(4):555-70. doi:10.1111/pcmr.12085

29. Ortiz R, Diaz J, Diaz N, Lobos-Gonzalez L, Cardenas A, Contreras P, et al. Extracellular matrix-specific caveolin-1 phosphorylation on tyrosine 14 is linked to augmented melanoma metastasis but not tumorigenesis. Oncotarget (2016) 7(26):40571-93. doi:10.18632/oncotarget.9738

30. Harris J, Werling D, Hope JC, Taylor G, Howard CJ. Caveolae and caveolin in immune cells: distribution and functions. Trends Immunol (2002) 23(3): 158-64. doi:10.1016/S1471-4906(01)02161-5

31. Tomassian T, Humphries LA, Liu SD, Silva O, Brooks DG, Miceli MC. Caveolin-1 orchestrates TCR synaptic polarity, signal specificity, and function in CD8 T cells. J Immunol (2011) 187(6):2993-3002. doi:10.4049/jimmunol. 1101447

32. Li J, Geng S, Xie X, Liu H, Zheng G, Sun X, et al. Caveolin-1-mediated negative signaling plays a critical role in the induction of regulatory dendritic cells by DNA and protein coimmunization. JImmunol (2012) 189(6):2852-9. doi:10.4049/jimmunol.1102828

33. Yang $\mathrm{Y}$, Xin Z, Chu J, Li N, Sun T. Involvement of caveolin-1 in CD83 internalization in mouse dendritic cells. Cell Transplant (2015) 24(7): 1395-404. doi:10.3727/096368914X682116

34. Wu B, Geng S, Bi Y, Liu H, Hu Y, Li X, et al. Herpes simplex virus 1 suppresses the function of lung dendritic cells via caveolin-1. Clin Vaccine Immunol (2015) 22(8):883-95. doi:10.1128/CVI.00170-15

35. van den Berg LM, Ribeiro CM, Zijlstra-Willems EM, de Witte L, Fluitsma D, Tigchelaar W, et al. Caveolin-1 mediated uptake via langerin restricts HIV-1 infection in human Langerhans cells. Retrovirology (2014) 11:123. doi:10.1186/s12977-014-0123-7

36. Polak ME, Thirdborough SM, Ung CY, Elliott T, Healy E, Freeman TC, et al. Distinct molecular signature of human skin Langerhans cells denotes critical differences in cutaneous dendritic cell immune regulation. J Invest Dermatol (2014) 134(3):695-703. doi:10.1038/jid.2013.375

37. Razani B, Engelman JA, Wang XB, Schubert W, Zhang XL, Marks CB, et al. Caveolin-1 null mice are viable but show evidence of hyperproliferative and vascular abnormalities. J Biol Chem (2001) 276(41):38121-38. doi:10.1074/jbc.M105408200

38. Allan RS, Waithman J, Bedoui S, Jones CM, Villadangos JA, Zhan Y, et al. Migratory dendritic cells transfer antigen to a lymph node-resident dendritic cell population for efficient CTL priming. Immunity (2006) 25(1):153-62. doi:10.1016/j.immuni.2006.04.017

39. Dearman RJ, Cumberbatch M, Hilton J, Clowes HM, Fielding I, Heylings JR, et al. Influence of dibutyl phthalate on dermal sensitization to fluorescein isothiocyanate. Fundam Appl Toxicol (1996) 33(1):24-30. doi:10.1006/faat. 1996.0139

40. Heuze ML, Collin O, Terriac E, Lennon-Dumenil AM, Piel M. Cell migration in confinement: a micro-channel-based assay. Methods Mol Biol (2011) 769:415-34. doi:10.1007/978-1-61779-207-6_28

41. Pflicke H, Sixt M. Preformed portals facilitate dendritic cell entry into afferent lymphatic vessels. J Exp Med (2009) 206(13):2925-35. doi:10.1084/ jem.20091739

42. Russo E, Nitschke M, Halin C. Dendritic cell interactions with lymphatic endothelium. Lymphat Res Biol (2013) 11(3):172-82. doi:10.1089/lrb.2013.0008

43. Rouzaut A, Garasa S, Teijeira A, Gonzalez I, Martinez-Forero I, Suarez N, et al. Dendritic cells adhere to and transmigrate across lymphatic endothelium in response to IFN-alpha. Eur J Immunol (2010) 40(11):3054-63. doi:10.1002/ eji.201040523 
44. Vaahtomeri K, Brown M, Hauschild R, De Vries I, Leithner AF, Mehling M, et al. Locally triggered release of the chemokine CCL21 promotes dendritic cell transmigration across lymphatic endothelia. Cell Rep (2017) 19(5):902-9. doi:10.1016/j.celrep.2017.04.027

45. Quast T, Eppler F, Semmling V, Schild C, Homsi Y, Levy S, et al. CD81 is essential for the formation of membrane protrusions and regulates Rac1activation in adhesion-dependent immune cell migration. Blood (2011) 118(7):1818-27. doi:10.1182/blood-2010-12-326595

46. Steinman RM, Banchereau J. Taking dendritic cells into medicine. Nature (2007) 449(7161):419-26. doi:10.1038/nature06175

47. Lei MG, Morrison DC. Differential expression of caveolin-1 in lipopolysaccharide-activated murine macrophages. Infect Immun (2000) 68(9):5084-9. doi:10.1128/IAI.68.9.5084-5089.2000

48. Ardeshna KM, Pizzey AR, Devereux S, Khwaja A. The PI3 kinase, p38 SAP kinase, and NF-kappaB signal transduction pathways are involved in the survival and maturation of lipopolysaccharide-stimulated human monocyte-derived dendritic cells. Blood (2000) 96(3):1039-46.

49. Tiruppathi C, Shimizu J, Miyawaki-Shimizu K, Vogel SM, Bair AM, Minshall RD, et al. Role of NF-kappaB-dependent caveolin-1 expression in the mechanism of increased endothelial permeability induced by lipopolysaccharide. J Biol Chem (2008) 283(7):4210-8. doi:10.1074/jbc.M703153200

50. Andreakos E, Sacre SM, Smith C, Lundberg A, Kiriakidis S, Stonehouse T, et al. Distinct pathways of LPS-induced NF-kappa B activation and cytokine production in human myeloid and nonmyeloid cells defined by selective utilization of MyD88 and Mal/TIRAP. Blood (2004) 103(6):2229-37. doi:10.1182/blood-2003-04-1356

51. Baeuerle PA. Pro-inflammatory signaling: last pieces in the NF-kappaB puzzle? Curr Biol (1998) 8(1):R19-22. doi:10.1016/S0960-9822(98)70010-7

52. Rescigno M, Martino M, Sutherland CL, Gold MR, Ricciardi-Castagnoli P. Dendritic cell survival and maturation are regulated by different signaling pathways. J Exp Med (1998) 188(11):2175-80. doi:10.1084/jem.188.11.2175

53. Stoitzner P, Zanella M, Ortner U, Lukas M, Tagwerker A, Janke K, et al. Migration of Langerhans cells and dermal dendritic cells in skin organ cultures: augmentation by TNF-alpha and IL-1beta. JLeukoc Biol (1999) 66(3):462-70.

54. Baluk P, Fuxe J, Hashizume H, Romano T, Lashnits E, Butz S, et al. Functionally specialized junctions between endothelial cells of lymphatic vessels. J Exp Med (2007) 204(10):2349-62. doi:10.1084/jem.20062596

55. Liao S, von der Weid PY. Lymphatic system: an active pathway for immune protection. Semin Cell Dev Biol (2015) 38:83-9. doi:10.1016/j.semcdb.2014.11.012

56. Jones EL, Wee JL, Demaria MC, Blakeley J, Ho PK, Vega-Ramos J, et al. Dendritic cell migration and antigen presentation are coordinated by the opposing functions of the tetraspanins CD82 and CD37. J Immunol (2016) 196(3):978-87. doi:10.4049/jimmunol.1500357
57. Oshita C, Takikawa M, Kume A, Miyata H, Ashizawa T, Iizuka A, et al. Dendritic cell-based vaccination in metastatic melanoma patients: phase II clinical trial. Oncol Rep (2012) 28(4):1131-8. doi:10.3892/or.2012.1956

58. Ahmed MS, Bae YS. Dendritic cell-based therapeutic cancer vaccines: past, present and future. Clin Exp Vaccine Res (2014) 3(2):113-6. doi:10.7774/ cevr.2014.3.2.113

59. Carreno BM, Magrini V, Becker-Hapak M, Kaabinejadian S, Hundal J, Petti AA, et al. Cancer immunotherapy. A dendritic cell vaccine increases the breadth and diversity of melanoma neoantigen-specific T cells. Science (2015) 348(6236):803-8. doi:10.1126/science.aaa3828

60. Lopez MN, Pereda C, Segal G, Munoz L, Aguilera R, Gonzalez FE, et al. Prolonged survival of dendritic cell-vaccinated melanoma patients correlates with tumor-specific delayed type IV hypersensitivity response and reduction of tumor growth factor beta-expressing T cells. J Clin Oncol (2009) 27(6):945-52. doi:10.1200/JCO.2008.18.0794

61. Mitchell DA, Batich KA, Gunn MD, Huang MN, Sanchez-Perez L, Nair SK, et al. Tetanus toxoid and CCL3 improve dendritic cell vaccines in mice and glioblastoma patients. Nature (2015) 519(7543):366-9. doi:10.1038/ nature 14320

62. Srinivas M, Aarntzen EH, Bulte JW, Oyen WJ, Heerschap A, de Vries IJ, et al. Imaging of cellular therapies. Adv Drug Deliv Rev (2010) 62(11):1080-93. doi:10.1016/j.addr.2010.08.009

63. Anguille S, Smits EL, Lion E, van Tendeloo VF, Berneman ZN. Clinical use of dendritic cells for cancer therapy. Lancet Oncol (2014) 15(7):e257-67. doi:10.1016/S1470-2045(13)70585-0

64. Faure-Andre G, Vargas P, Yuseff MI, Heuze M, Diaz J, Lankar D, et al. Regulation of dendritic cell migration by CD74, the MHC class II-associated invariant chain. Science (2008) 322(5908):1705-10. doi:10.1126/science.1159894

65. Vargas P, Maiuri P, Bretou M, Saez PJ, Pierobon P, Maurin M, et al. Innate control of actin nucleation determines two distinct migration behaviours in dendritic cells. Nat Cell Biol (2016) 18(1):43-53. doi:10.1038/ncb3284

Conflict of Interest Statement: The authors declare that the research was conducted in the absence of any commercial or financial relationships that could be construed as a potential conflict of interest.

Copyright $\odot 2017$ Oyarce, Cruz-Gomez, Galvez-Cancino, Vargas, Moreau, DiazValdivia, Diaz, Salazar-Onfray, Pacheco, Lennon-Dumenil, Quest and Lladser. This is an open-access article distributed under the terms of the Creative Commons Attribution License (CC BY). The use, distribution or reproduction in other forums is permitted, provided the original author(s) or licensor are credited and that the original publication in this journal is cited, in accordance with accepted academic practice. No use, distribution or reproduction is permitted which does not comply with these terms. 